\title{
Relationship between Changes in Cerebral Blood Flow with Symptoms of Acute Mountain Sickness in Men Repeatedly Exposed to Simulated High Altitude
}

\author{
Peter Ondruš' ${ }^{1}$, Roman Alberty ${ }^{2}$, Timothy Lyons ${ }^{1}$, Stephen Muza1, Vincent Echavé ${ }^{3}$, \\ Jacques Poisson ${ }^{3}$, Allen Cymerman ${ }^{1}$
${ }^{1}$ Altitude Physiology \& Medicine Division, US Army Research Institute for Environmental Medicine, Natick, MA, USA
${ }^{2}$ Department of Biology \& Ecology, Matthias Belivs University, Banská Bystrica, Slovakia
${ }^{3}$ Department of Surgery, Sherbrooke University Hospital, Sherbrooke, Canada \\ Email: roman.alberty@umb.sk
}

\begin{abstract}
How to cite this paper: Ondruš, $\mathrm{P} ., \mathrm{Al}-$ berty, R., Lyons, T., Muza, S., Echavé, V., Poisson, J., \& Cymerman, A. (2017). Relationship between Changes in Cerebral Blood Flow with Symptoms of Acute Mountain Sickness in Men Repeatedly Exposed to Simulated High Altitude. Advances in Physical Education, 7, 49-59.

https://doi.org/10.4236/ape.2017.71005
\end{abstract}

Received: January 19, 2017

Accepted: February 24, 2017

Published: February 27, 2017

Copyright $\odot 2017$ by authors and Scientific Research Publishing Inc. This work is licensed under the Creative Commons Attribution International License (CC BY 4.0).

http://creativecommons.org/licenses/by/4.0/

\begin{abstract}
Objective: To study the relationship between changes in the cerebral blood flow (CBF) velocity with symptoms of acute mountain sickness (AMS) during simulated high altitude. Research Design and Methods: Mean middle arterial cerebral flow velocity (MCAv) was assessed by transcranial Doppler sonography in 8 healthy lowland male adults aged $20-24$ yrs before and after $6 \mathrm{~h}$ and $48 \mathrm{~h}$ at simulated altitude corresponding to $4572 \mathrm{~m}$. The same study was repeated three weeks later in the same subjects. End-tidal $\mathrm{pCO}_{2}\left(\mathrm{ETCO}_{2}\right)$ and arterial oxygen saturation $\left(\mathrm{SaO}_{2}\right)$ were measured by standardized procedures. AMS symptoms were recorded using the modified environmental symptoms questionnaire after $6 \mathrm{~h}$ and $48 \mathrm{~h}$ exposure to calculate the mean score of cerebral (AMS-C) symptoms. Results: Mean MCAv significantly increased with high altitude (HA) by $4 \%$ at $6 \mathrm{~h} \mathrm{HA}$ and $24 \%$ at $48 \mathrm{~h} \mathrm{HA}(P<0.05)$ compared to sea-level values. We observed a substantial inter-subject variance in MCAv changes, especially in the first hours upon altitude exposure. Within first 2 days, we found a moderate positive correlation between MCAv with decreased $\mathrm{ETCO}_{2}$ (mean $\pm \mathrm{SD} 32 \pm 4 \mathrm{mmHg} ; \mathrm{r}=0.47, P<0.05$ ), and a weak negative correlation of MCAv with a similar low $\mathrm{SaO}_{2}(77 \% \pm 8 \% ; \mathrm{r}=-0.43, P<0.05)$. Five of the 10 original subjects developed symptoms of AMS; however, AMS-C scores decreased $(P=0.08)$ with increased duration of exposure (6 h HA 0.91 \pm 1.09 vs $48 \mathrm{~h}$ HA $0.39 \pm 0.40)$. No differences in AMS-C scores were observed when subjects with and without increased MCAv were compared at $6 \mathrm{~h}$ $\mathrm{HA}$ and $48 \mathrm{~h}$ HA. Furthermore, there was no correlation between changes in neither absolute nor relative MCAv and AMS-C scores. Severity of AMS symp-
\end{abstract}


toms coincided well with reduction in $\mathrm{SaO}_{2}(\mathrm{r}=-0.55, P<0.05)$. Conclusion: Our results suggest that there is a lack of relationship between changes in CBF velocity with symptoms of AMS, and that a substantial inter-subject variance exists in the $\mathrm{CBF}$ response to high altitude exposure.

\section{Keywords}

High-Altitude Sickness, Cerebral Blood Flow, Hypobaric Hypoxia, Transcranial Doppler Sonography

\section{Introduction}

Acute mountain sickness (AMS), characterized by headache, dizziness, nausea, breathlessness, fatigue and insomnia, may occur during rapid ascent to altitudes above $2500 \mathrm{~m}$, in humans poorly acclimatized to such extreme conditions. Symptoms of AMS begin to show for 6 - 24 hours after high altitude exposure due to a delayed physiological response to reduced air pressure and lower oxygen concentration (West, Schoene, Luks, \& Milledge, 2012).

The precise pathophysiology of AMS is not known, however, on the basis of early findings increased cerebral blood flow (CBF) in the first few hours of high altitude exposure may play an important role in the pathogenesis of AMS (Huang et al., 1987; Lassen, 1992; Baumgartner et al., 1994). Although early findings indicate that increased $\mathrm{CBF}$ is higher in those with AMS than those without AMS symptoms (Baumgartner et al., 1994), this has not been confirmed in later studies (Baumgartner et al., 1999; Dyer et al., 2008; Lucas et al., 2011). Recent field altitude studies demonstrated that the changes in CBF (velocity) show no clear relationship to symptoms of AMS, at least in the first hours at high altitude (Subudhi et al. 2014; Bian et al., 2014; Imray et al., 2014). Therefore, some authors concluded that CBF is not a relevant factor in the pathogenesis of AMS (Baumgartner et al., 1999).

The current study was carried out to study the relationship between changes in CBF velocity with symptoms of AMS in a group of healthy lowland young males during a $48 \mathrm{~h}$ decompression to a simulated altitude of $4572 \mathrm{~m}$. (This study of CBF originated as self-employed part of a more comprehensive study investigating high altitude physiology of acute mountain sickness in US Army Research Institute for Environmental Medicine).

\section{Material and Methods}

\subsection{Subjects}

All of the original 10 volunteers were US male soldiers between the ages 20 - 24 years with a mean body weight $73 \pm 10 \mathrm{~kg}$ and without any known medical or mental illness. Specific inclusion criteria included a lifelong low altitude residence and no exposure to altitude higher than $1000 \mathrm{~m}$ for at least 6 months immediately before this study. The subjects were not taking any medication at time 
of the study, all were normotensive and had no history of cardiovascular, cerebrovascular or respiratory disease. All signed an informed consent with the US Army Research Institute for Environmental Medicine for participation in the high altitude sickness study. Volunteers could desert the study at any time. Constant medical attention and care by physicians was provided for the entire duration of the study.

\subsection{Study Design}

For each exposure, baseline examination of CBF velocity by means of transcranial Doppler (TCD) assessment was performed in a hypobaric chamber at an altitude of $50 \mathrm{~m}$ (barometric pressure, $755 \mathrm{mmHg}$; temperature, $20^{\circ} \mathrm{C}$ ) in the Army Research Institute of Environmental Medicine (Natick, MA, USA). The next morning, the chamber was decompressed to $429 \mathrm{mmHg}$ over $15 \mathrm{~min}$, simulating an altitude of $4572 \mathrm{~m}$ (hypobaric hypoxia). Two further TCD studies of $\mathrm{CBF}$ velocity were carried out at $6 \mathrm{~h}$ and $48 \mathrm{~h}$ after high altitude exposure. Volunteers remained in the decompressed chamber for $72 \mathrm{~h}$, except for an approximate $2 \mathrm{~h}$ period (normobaric hypoxia; non-rebreathing face mask with $\mathrm{O}_{2}$ partial pressure at the altitude of $4572 \mathrm{~m}$ ) after $32 \mathrm{~h}$ when they were transferred to the MR imaging scanner site (Brigham \& Women Hospital, Boston, MA, USA) to quantify possible brain swelling (Mórocz et al., 2001). Three weeks after the first altitude exposure (exposure I) the second altitude exposure (exposure II) was performed at the same laboratory conditions.

\subsection{Transcranial Doppler Ultrasound Examination}

CBF velocity was estimated by the measurement of middle cerebral artery blood flow velocity (MCAv) at a depth of 50 to $55 \mathrm{~mm}$ using a 2-MHz pulsed MultiDop T device (DWL Elektronische Systeme GmbH, Sipplingen, Germany). The monitoring $2-\mathrm{MHz}$ probe was fixed with a specially designed glasses type holder, allowing continuous recording without modification of the insonation angle. The mean MCAv in left middle cerebral artery was averaged from the nine minutes of continuous recording of arterial TCD signal. Mean MCAv obtained in each individual was used for further statistical analysis. All TCD examinations were performed by the same examiner (P. Ondruš).

\subsection{Arterial Oxygen Saturation and End-Tidal $\mathrm{CO}_{2}$}

Resting arterial oxygen saturation $\left(\mathrm{SaO}_{2}\right)$ was measured by pulse oximetry, and the end-tidal $\mathrm{CO}_{2}\left(\mathrm{ETCO}_{2}\right)$ tension by rapidly responding analyzers (LB-2; Beckman Coulter, Anaheim, CA, USA and S3-A; Applied Electrochemistry Inc., Sunnyvale, CA, USA, respectively).

\subsection{Assessment of Acute Mountain Sickness}

The diagnosis and severity of AMS was assessed utilizing the Environmental Symptoms Questionnaire (ESQ), which was administered at $06.00 \mathrm{~h}, 12.00 \mathrm{~h}$, and $20.00 \mathrm{~h}$ during hypoxic exposure. In order to determine the presence of 
AMS, a weighted average of cerebral symptoms (AMS-C) was calculated from the ESQ scores. AMS-C score of $>0.7$ indicates the presence of AMS (Sampson et al., 1983).

\subsection{Statistical Analysis}

Intra- and inter-subject comparisons were analyzed using a paired $t$-test, and one-way ANOVA with Bonferroni multiple analysis. The relationship between$\mathrm{SaO}_{2}, \mathrm{ETCO}_{2}$ or AMS-C score and the changes in \%MCAv from that at sea-level were determined by Pearson correlation analysis. Significance was accepted at $P<$ 0.05, two-tailed. The PASW statistics 19.0 (SPSS Inc. Chicago, IL, USA) was used for statistical analysis.

\section{Results}

Eight of the ten volunteers fulfilled the criteria for at least one high altitude exposure and underwent the TCD and blood gas examinations. One of the 10 original volunteers had to leave the study due to clinical symptoms of AMS (AMS-C score 3.4) after a few hours of hypobaric exposure, and data obtained from another subject were excluded for missing a TCD examination. Three weeks later, six volunteers ( 2 of remaining 8 subjects voluntarily quit the study) repeated the hypobaric hypoxia exposure II. During exposure I, 3 of the 8 subjects developed AMS while during exposure II, 2 of 6 subjects sustained AMS.

Changes in mean MCA velocity, AMS-C score, $\mathrm{SaO}_{2}$ and $\mathrm{ETCO}_{2}$ summarized across exposures I and II are shown in Table 1.

Mean MCAv increased $(P=0.02)$ during high altitude (HA) from baseline values 53.8 to $56.1(+4.2 \%)$ and $66.8(+24.2 \%) \mathrm{cm} \cdot \mathrm{s}^{-1}$ at $6 \mathrm{~h} \mathrm{HA}$ and $48 \mathrm{~h} \mathrm{HA}$, respectively. During a period of $6 \mathrm{~h} \mathrm{HA}$, the MCAv increased in 7 subjects, but remained unchanged or decreased in 5. Thus there was a substantial inter-subject variance in CBF velocity, especially in the early state of altitude exposure. However, our data suggest that the increase in MCAv during the exposure I was also observed in the exposure II ( 6 h HA $56.4 \pm 12.3$ vs $55.0 \pm 13.6$ and $48 \mathrm{~h} \mathrm{HA}$ $\left.68.1 \pm 13.5 \mathrm{vs} 66.4 \pm 14.0 \mathrm{~cm} \cdot \mathrm{s}^{-1}, P=0.83-0.85\right)$, irrespective of AMS-C score. Individual measurements of $\mathrm{CBF}$ before and during the first and second altitude exposure are shown in Figure 1.

Table 1. Mean MCA flow velocity, acute mountain sickness-cerebral score, arterial $\mathrm{O}_{2}$ saturation, and end-tidal $\mathrm{CO}_{2}$ during decompression to $4557 \mathrm{~m}$.

\begin{tabular}{|c|c|c|c|c|c|c|}
\hline \multicolumn{2}{|c|}{ Altitude } & \multicolumn{2}{|c|}{ MCAv } & \multirow[b]{2}{*}{ AMS-C score } & \multirow[b]{2}{*}{$\mathrm{SaO}_{2}(\%)$} & \multirow{2}{*}{$\begin{array}{c}\mathrm{ETCO}_{2} \\
(\mathrm{~mm} \mathrm{Hg})\end{array}$} \\
\hline Height (m) & $\begin{array}{c}\text { Time } \\
\text { (hours) }\end{array}$ & $\mathrm{cm} \cdot \mathrm{s}^{-1}$ & $\%$ sea level & & & \\
\hline$<50$ & 0 & $53.8 \pm 6.3^{*}$ & 100 & - & - & - \\
\hline 4572 & 6 & $56.1 \pm 12.9$ & $104.2 \pm 23.8$ & $0.91 \pm 1.09$ & $77.1 \pm 8.8$ & $32.9 \pm 4.0$ \\
\hline 4572 & 48 & $66.8 \pm 14.2$ & $124.2 \pm 26.2$ & $0.39 \pm 0.40$ & $77.9 \pm 5.6$ & $31.0 \pm 2.8$ \\
\hline$P$ ANOVA & & 0.02 & 0.00 & 0.08 & 0.54 & 0.01 \\
\hline
\end{tabular}

${ }^{\star}$ Data are expressed as mean \pm SD (calculated across altitude exposures I and II). 


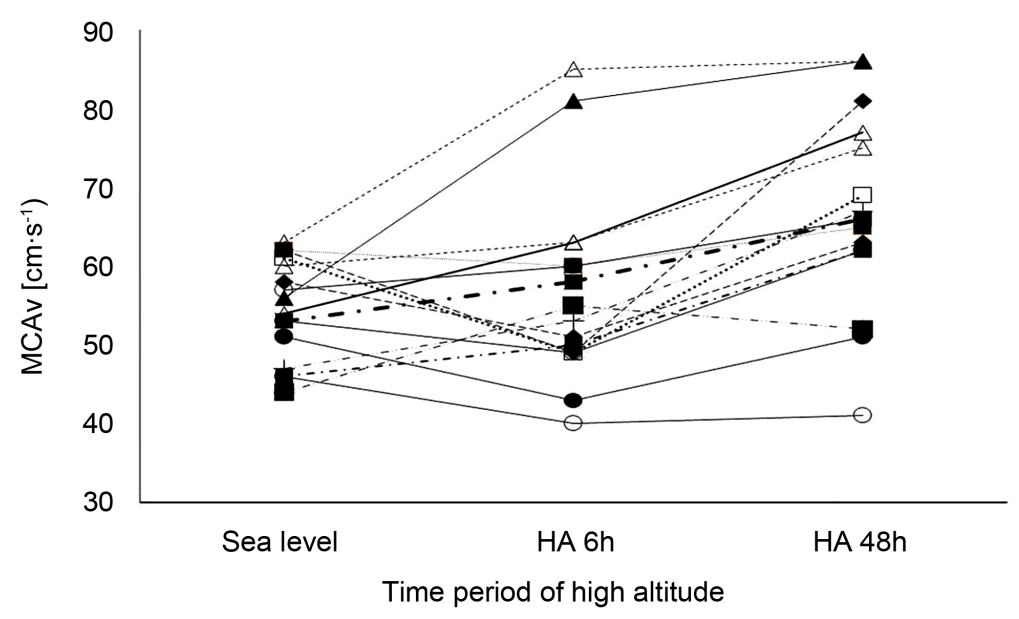

Figure 1. Individual measurements in MCAv before and during the first $(\bullet)$ and second altitude exposure (०).

The AMS-C scores decreased $(P=0.08)$ with increased duration of exposure (mean $\pm \mathrm{SD} 0.91 \pm 1.09$ at $6 \mathrm{~h} \mathrm{HA}$ vs $0.39 \pm 0.40$ at $48 \mathrm{~h} \mathrm{HA}$ ). No difference in AMS-C scores was observed when subjects with and without increased MCAv were compared at $6 \mathrm{~h}$ HA versus $48 \mathrm{~h}$ HA. In this context, the changes in \%MCAv did not correlate with AMS-C score $(\mathrm{r}=-0.10, P=0.69)$ during the first $48 \mathrm{~h}$ of altitude exposure (Figure 2). In contrast, severity of AMS symptoms coincided well with reduction in $\mathrm{SaO}_{2}$ at $48 \mathrm{~h} \mathrm{HA}(\mathrm{r}=-0.55, P<0.05)$.

Both $\mathrm{SaO}_{2}$ and $\mathrm{ETCO}_{2}$ were decreased over time during altitude exposure (77\% $\pm 8 \%$ and $32 \pm 4 \mathrm{mmHg}$, respectively); the lower concentrations remained unchanged for the entire length of the study. $\mathrm{SaO}_{2}$ as well as $\mathrm{ETCO}_{2}$ showed difference $(P<0.05)$ when subjects with and without increased MCAv were compared at $6 \mathrm{~h} \mathrm{HA}$, but not at $48 \mathrm{~h} \mathrm{HA}$. During altitude exposure, the changes in \%MCAv correlated positively with probably decreased $\mathrm{ETCO}_{2}(32 \pm 4 \mathrm{~mm}$ $\mathrm{Hg} ; \mathrm{r}=0.47, P<0.05)$ and negatively with a similar low $\mathrm{SaO}_{2}(77 \% \pm 8 \% ; \mathrm{r}=$ $-0.43, P<0.05)$ (Figure 3 and Figure 4 ).

\section{Discussion}

In this study we examined the relationship between changes in CBF velocity with symptoms of AMS in a group of lowland male subjects at a simulated altitude of $4572 \mathrm{~m}$. The major findings of the current study showed that mean MCAv significantly increased within the first 2 days of altitude exposure, and suggested a lack of a (linear) relationship between MCAv and symptoms of AMS. However, immediately upon altitude exposure, the mean MCAv remained essentially unchanged or even decreased in the most of study subjects.

Our findings are consistent with reports of several field or chamber studies focusing on acclimatization to hypoxia at high altitudes over a period of hours to days. Baumgartner et al. (1999) reported, in similarly aged men, an unchanged mean MCAv with a small relative rise ( $\sim 9 \%)$ compared with baseline values after 6 hours of exposure at altitude of $4559 \mathrm{~m}$. In this same chamber study, the 


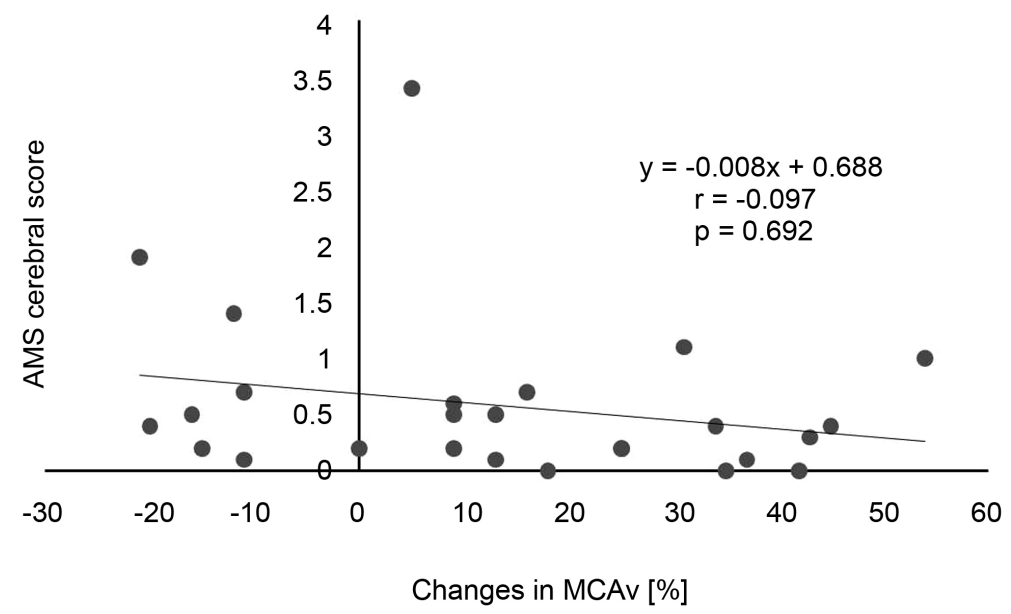

Figure 2. Relation between changes in MCAv and AMS-C score.

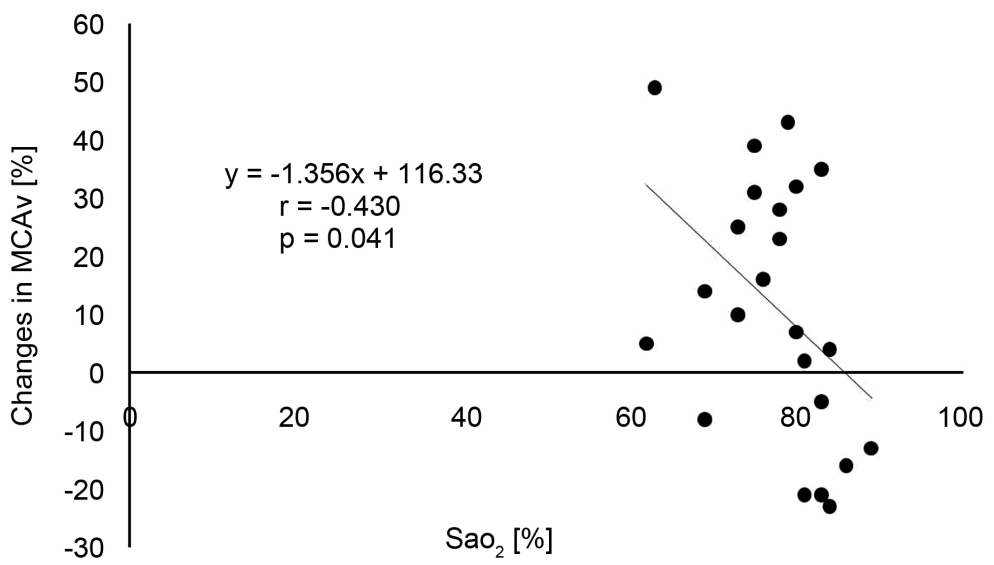

Figure 3. Relation between changes in MCAv and arterial oxygen saturation.

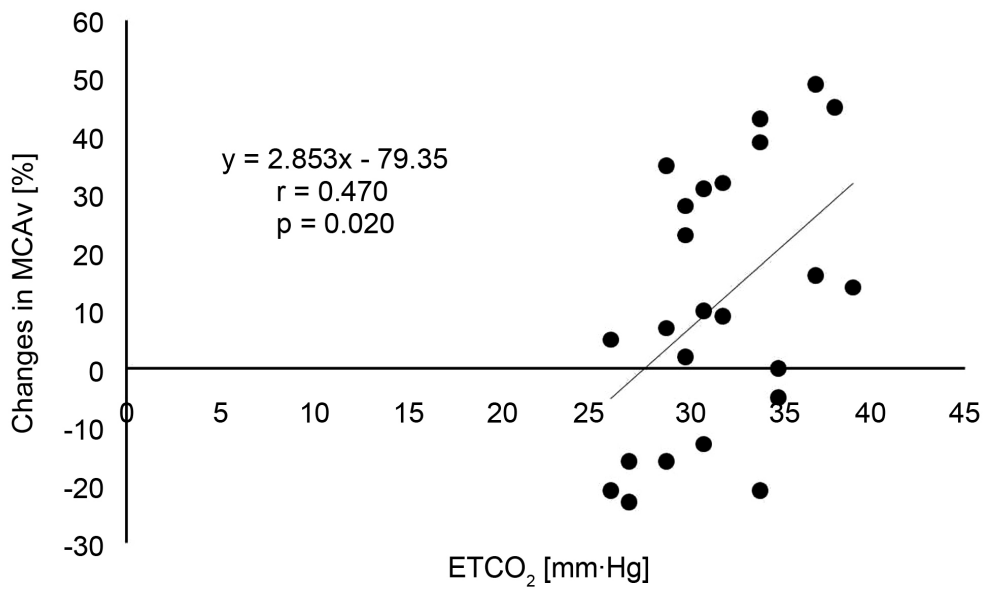

Figure 4. Relation between changes in MCAv and end-tidal carbon dioxide.

changes in MCAv did not correlate with AMS-C scores. Subudhi et al. (2014) examined acute response of $\mathrm{CBF}$ in 21 healthy volunteers rapidly ascended to $5260 \mathrm{~m}$ (Chacaltaya, Bolivia). Although CBF increased globally by $~ 70 \%$ within 2 - $4 \mathrm{~h}$ of altitude, the mean MCAv remained unchanged in comparison with 
baseline values. Furthermore, changes in CBF were not associated with the incidence or severity of AMS. In another field study, Lucas et al. (2011) found in healthy young 11 males and 6 females that upon initial arrival at an altitude of 5050 m (Khumbu Valley, Nepal) mean MCAv was elevated (up 30\% vs sea-level), but returned to sea-level values within 7 - 9 days. The balance of arterial blood gases oxygen/carbon dioxide accounted for a large part $(\sim 40 \%)$ of the observed variability leading to changes in CBF at high altitude. Poulin et al. (2002) described in nine healthy subjects ( 6 males, 3 females) a decline in CBF to values below the initial control value after $24 \mathrm{~h}$ of simulated altitude exposure for arterial $P_{\mathrm{O} 2}$ of 60 Torr (equivalent to altitude of $\sim 2800 \mathrm{~m}$ and $\sim 3400 \mathrm{~m}$ for non-responders and responders, respectively), followed by a subsequent rise within $48 \mathrm{~h}$. The changes in CBF velocity were very closely related to changes in end-tidal $\mathrm{CO}_{2}$ tension.

The general consensus is that upon acute exposure to altitude CBF initially rises and returns to near baseline values within the first few days or 1 - 2 weeks of acclimatization (Huang et al., 1987; Jensen et al., 1990; Baumgartner et al., 1994; Lucas et al., 2011; Subudhi et al., 2014). The magnitude in the changes in $\mathrm{CBF}$ after altitude exposure depend upon two stimuli with opposing influences on the cerebral circulation: arterial hypoxia and arterial hypocapnia. Arterial hypoxia arises as a ventilatory response to reduced air pressure and lower oxygen concentration in high altitude and tends to cause vasodilatation (Wilson et al., 2011; Imray et al., 2014), whereas arterial hypocapnia occurs as a consequence of the reflex hyperventilation and may cause vasoconstriction (Atkinson, Anderson \& Sundt Jr., 1990). Moreover, these stimuli are not constant over time if one remains at a constant altitude because in prolonged hypoxic conditions, arterial hypoxia is reduced and $\mathrm{CBF}$ undergone some degree of adaptation to hypocapnia (Poulin et al., 2002). In this context, it is clear that differences in the magnitude of these mechanisms may cause the well-known intra- and inter-individual variance in changes in CBF after initial altitude exposure (Baumgartner et al., 1999).

In our study, the mean MCAv remained unchanged at $6 \mathrm{~h}$ after acute exposure to altitude. One possible explanation of the failure of increased flow velocity upon simulated altitude may be small or delayed influence of the respiratory gases on the cerebral blood circulation in the early period of altitude. However, it seems highly unlikely because in our subjects, MCAv was permanently and significantly related to variations in $\mathrm{ETCO}_{2}$ tension. It seems that an initial hypocapnia probably has the predominant effect and inhibits the possible initial hypoxic cerebral vasodilation. Therefore, CBF velocity remains essentially unchanged or may diminish below starting sea-level values in the early stage of altitude exposure. Of course, as time progresses, the rise in $\mathrm{CBF}$ observed in our and aforementioned studies may be the result of increased sensitivity of CBF to acute variations in both hypoxia and increased $\mathrm{CO}_{2}$ during the $48 \mathrm{~h}$ of hypoxia (Poulin et al., 2002).

Our study of CBF was performed in conjunction with a study that used a nov- 
el MR imaging technique to examine cerebral tissue volume before and after high altitude exposure in the same subjects within the same study. Specifically, alterations in $\mathrm{CBF}$, brain volume and intracranial pressure may play critical roles in the development of AMS, particularly the neurological symptoms, headache and dizziness (Imray, Wright, Subudhi, \& Roach, 2010). The chamber values for cerebral tissue swelling due to hypobaric hypoxia have been reported previously (Mórocz et al., 2001). In brief, a significant $(P<0.001)$ brain swelling of $36.2 \pm$ $19.6 \mathrm{ml}(2.8 \% \pm 1.5 \%)$ develops after $32 \mathrm{~h}$ of hypobaric hypoxia. The brain edema in our subjects was diffuse in nature, having a predominantly gray mater origin, and without significant relation to AMS-C score. Yet the combination of these brain tissue volume data with the additional CBF values from our study indicate a weak association between changes in brain tissue volume and CBF variations (Figure 5).

Several studies considered increased CBF after high altitude exposure as an important co-factor in the etiology of AMS (Jensen et al., 1990; Van Osta et al., 2005). In our study, five of the original 10 subjects had clinical symptoms of AMS in at least one of the high altitude exposure studies. One subject had to quit the study within a few hours of exposure, suffering from headache, nausea and general discomfort. According to our medical records, the symptoms of AMS occurred in the same three subjects in both altitude exposures. Most volunteers reported mild symptoms of AMS within 6 - 24 h of hypobaric hypoxia; however, only 4 out of 12 subjects met clinical definition of AMS. Adaptation to hypoxia/hypocapnia during prolonged hypobaric conditions most likely explains the observed decrease of AMS-C score with increasing duration of high altitude exposure. Severity of AMS symptoms in our subjects coincided well with reduction in arterial oxygen saturation as described previously Hussain et al. (2001).

In recent studies, the pathogenic role of CBF in the etiology of AMS has been doubted. In support of this conclusion, Ainslie \& Subudhi (2014) provided convincing data from four different field studies looking at individual measurements of $\mathrm{CBF}$ and AMS symptoms, showing no direct association. Additionally,

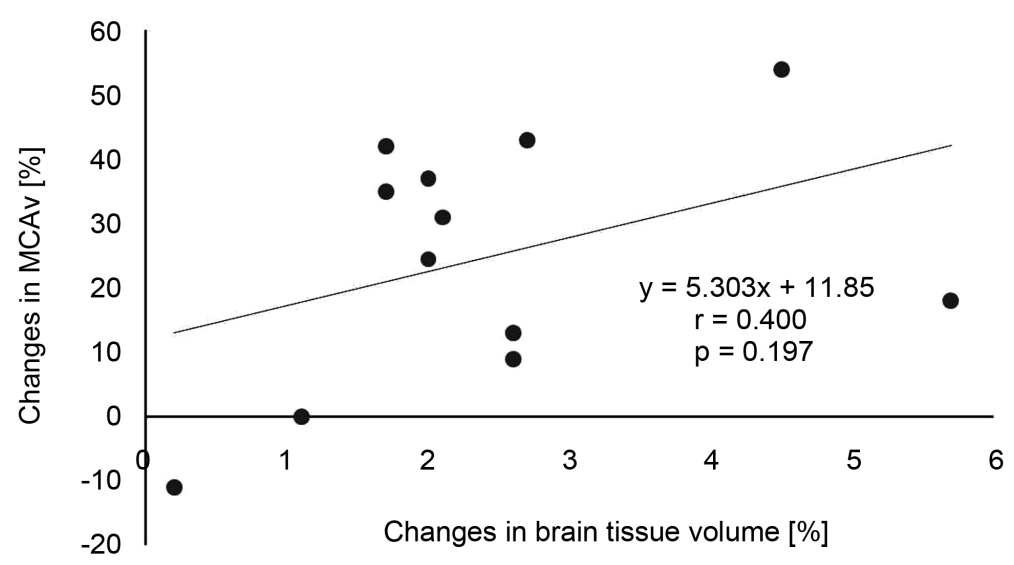

Figure 5. Relation between changes in MCAv and brain tissue volume. Data combined from altitude chamber study (Mórocz et al., 2001). 
altitude chamber studies revealed that the CBF velocity measured in the middle cerebral artery is substantially unchanged compared to sea-level value, and, moreover, with no clear relationship to symptoms of AMS, at least in the first few hours of simulated altitude (Baumgartner et al., 1999; Subudhi et al., 2014). Our findings solidly confirmed the lack of relationship between changes in CBF with symptoms of AMS, at least in the first two days of high altitude exposure.

However, these results should be interpreted with caution because it is possible that: 1) changes in a global CBF may not reflect the changes in the small cerebral vessels that likely have greater contribution to the symptomatology of AMS, 2) other risk factors associated with increased CBF that may cause AMS, especially metabolic, genetic and endocrine factors, and 3) our measurements were carried out in highly controlled laboratory conditions i.e. in an altitude chamber with the absence of cold, stress, exercise, exhaustion, dehydratation and other influences associated with mountaineering.

One major limitation of this study is the small sample size due to the possible health hazards in unpleasant hypoxic conditions. However, we are confident about the observed trends and relative changes in CBF velocity in our altitude chamber experiment.

\section{Conclusion}

The current study suggests that changes in $\mathrm{CBF}$ alone are not a causative factor for the development of AMS (or brain swelling). In overall, the CBF values remain unchanged within the first few hours after altitude exposure, followed by subsequent progressive increase at $48 \mathrm{~h}$. CBF is more sensitive to the variations in the end-tidal $\mathrm{CO}_{2}$ than in the $\mathrm{SaO}_{2}$ concentration. Furthermore, we demonstrate a substantial inter-individual variance in CBF response to high altitude exposure. Further studies are needed to investigate the tiny regulators (nitric oxide, adenosine, calcitonin gene-related peptide, etc.) with great potential for $\mathrm{CBF}$ regulation and brain function at high altitude.

\section{Conflict of Interest}

There is no conflict of interest.

\section{References}

Ainslie, P. N., \& Subudhi, A. W. (2014). Cerebral Blood Flow at High Altitude. High Altitude Medicine \& Biology, 15, 133-140. https://doi.org/10.1089/ham.2013.1138

Atkinson, J. L., Anderson, R. E., \& Sundt, T. J. (1990). The Effect of Carbon Dioxide on the Diameter of Brain Capillaries. Brain Research, 517, 333-340. https://doi.org/10.1016/0006-8993(90)91046-J

Baumgartner, R. W., Bartsch, P., Maggiorini, M., Waber, U., \& Oelz, O. (1994). Enhanced Cerebral Blood Flow in Acute Mountain Sickness. Aviation, Space, and Environmental Medicine, 65, 726-729.

Baumgartner, R. W., Spyridopoulos, I., Bartsch, P., Maggiorini, M., \& Oelz, O. (1999). Acute Mountain Sickness Is Not Related to Cerebral Blood Flow: A Decompression Chamber Study. Journal of Applied Physiology, 86, 1578-1582. 
Bian, S.-Z., Jin, J., Li, Q.-N., Qin, J., Zhang, J.-H., Yu, S.-Y., Chen, J.-F., Tang, C.-F., \& Huang, L. (2014). Cerebral Hemodynamic Characteristics of Acute Mountain Sickness upon High-Altitude Exposure at 3,700 $\mathrm{m}$ in Young Chinese Men. European Journal of Applied Physiology, 114, 2193-2200. https://doi.org/10.1007/s00421-014-2934-6

Dyer, E. A., Hopkins, S. R., Perthen, J. E., Buxton, R. B., \& Dubowitz, D. J. (2008). Regional Cerebral Blood Flow during Acute Hypoxia in Individuals Susceptible to Acute Mountain Sickness. Respiratory Physiology \& Neurobiology, 160, 267-276. https://doi.org/10.1016/j.resp.2007.10.010

Huang, S. V., Moore, L. G., McCullough, R. E., Micco, A. J., Fulco, C., Cymerman, A., Manco-Johnson, M., Weil, J. V., \& Reeves, J. T. (1987). Internal Carotid and Vertebral Arterial Flow Velocity in Men at High Altitude. Journal of Applied Physiology, 63, 395-400.

Hussain, M. M., Aslam, M., \& Khan, Z. (2001). Acute Mountain Sickness Score and Hypoxemia. Journal of the Pakistan Medical Association, 51, 173-179.

Imray, C., Chan, C., Stubbings, A., Rhodes, H., Patey, S., Wilson, M. H., Bailey, D. M., \& Wright, A. D. (2014). Time Course Variations in the Mechanisms by Which Cerebral Oxygen Delivery Is Maintained on Exposure to Hypoxia/Altitude. High Altitude Medicine \& Biology, 15, 21-27. https://doi.org/10.1089/ham.2013.1079

Imray, C., Wright, A., Subudhi, A., \& Roach, R. (2010). Acute Mountain Sickness: Pathophysiology, Prevention, and Treatment. Progress in Cardiovascular Diseases, 52, 467-484. https://doi.org/10.1016/j.pcad.2010.02.003

Jensen, J. B., Wright, A. D., Lassen, N. A., Harvey, T. C., Winterborn, M. H., Raichle, M. E., \& Bradwell, A. R. (1990). Cerebral Blood Flow in Acute Mountain Sickness. Journal of Applied Physiology, 69, 430-433.

Lassen, N. A. (1992). Increase of Blood Flow at High Altitude: Its Possible Relation to AMS. International Journal of Sports Medicine, 13, S47-S48.

https://doi.org/10.1055/s-2007-1024591

Lucas, S. J. E., Burgess, K. R., Thomas, K. N., Donnelly, J., Peebles, K. C., Lucas, R. A. I., Fan, J.-L., Cotter, J. D., Basnyat, R., \& Ainslie, P. N. (2011). Alterations in Cerebral Blood Flow and Cerebrovascular Reactivity during 14 Days at $5050 \mathrm{~m}$. Journal of Physiology, 589, 741-753. https://doi.org/10.1113/jphysiol.2010.192534

Mórocz, I. A., Zientara, G. P., Gudbjartsson, H., Muza, S., Lyons, T., Rock, P. B., Kikinis, R., \& Jólesz, F. A. (2001). Volumetric Quantification of Brain Swelling after Hypobaric Hypoxia Exposure. Experimental Neurology, 168, 96-104.

https://doi.org/10.1006/exnr.2000.7596

Poulin, M. J., Fatemian, M., Tansley, J. G., O'connor, D. F., \& Robbins, P. A. (2002). Changes in Cerebral Blood Flow during and after $48 \mathrm{~h}$ of Both Isocapnic and Poikilocapnic Hypoxia in Humans. Experimental Physiology, 87, 633-642. https://doi.org/10.1113/eph8702437

Sampson, J. B., Cymerman, A., Burse, R. J., Maher, J. T., \& Rock, P. N. (1983). Procedures for the Measurement of Acute Mountain Sickness. Aviation, Space, and Environmental Medicine, 54, 1063-1073.

Subudhi, A. W., Fan, J.-L., Evero, O., Bourdillon, N., Kayser, B., Julian, C. G., Lovering, A. T., \& Roach, R. C. (2014). Altitude Omics: Effect of Ascent and Acclimatization to $5260 \mathrm{~m}$ on Regional Cerebral Oxygen Delivery. Experimental Physiology, 99, 772-781. https://doi.org/10.1113/expphysiol.2013.075184

Van Osta, A., Moraine, J. J., Mélot, C., Mairbaurl, H., Maggiorini, M., \& Nacije, R. (2005). Effects of High Altitude Exposure on Cerebral Hemodynamics in Normal Subjects. Stroke, 36, 557-560. https://doi.org/10.1161/01.STR.0000155735.85888.13

West, J. B., Schoene, R. B., Luks, A. M., \& Milledge, J. S. (2012). High Altitude Medicine 
and Physiology (5th ed.). Boca Raton, FL: CRC Press. https://doi.org/10.1201/b13633

Wilson, M. H., Edsell, M. E., Davagnanam, I., Hirani, S. P., Martin, D. S., Levett, D. Z. H., Thornton, J. S. et al. (2011). Cerebral Artery Dilatation Maintains Cerebral Oxygenation at Extreme Altitude and in Acute Hypoxia-An Ultrasound and MRI Study. Journal of Cerebral Blood Flow \& Metabolism, 31, 2019-2029.

https://doi.org/10.1038/jcbfm.2011.81

\section{* Scientific Research Publishing}

Submit or recommend next manuscript to SCIRP and we will provide best service for you:

Accepting pre-submission inquiries through Email, Facebook, LinkedIn, Twitter, etc. A wide selection of journals (inclusive of 9 subjects, more than 200 journals)

Providing 24-hour high-quality service

User-friendly online submission system

Fair and swift peer-review system

Efficient typesetting and proofreading procedure

Display of the result of downloads and visits, as well as the number of cited articles Maximum dissemination of your research work

Submit your manuscript at: http://papersubmission.scirp.org/

Or contact ape@scirp.org 